\title{
Correction to: Trends in Organize Crime, Volume 22, issue 4
}

\section{Springer Nature ${ }^{1}$}

Published online: 20 December 2019

(C) Springer Science+Business Media, LLC, part of Springer Nature 2019

\section{Correction to: Trends Organ Crim (2019) 22(4) \\ https://doi.org/10.1007/s12117-018-9342-y \\ https://doi.org/10.1007/s12117-018-9345-8 \\ https://doi.org/10.1007/s12117-018-9356-5 \\ https://doi.org/10.1007/s12117-018-9350-y \\ https://doi.org/10.1007/s12117-018-9335-x \\ https://doi.org/10.1007/s12117-018-9353-8}

The Publisher regrets an error on the cover date of the December 2019 issue. The cover date was incorrectly listed as December 15, 2000. The correct cover date should be: December 15, 2019.

Publisher's note Springer Nature remains neutral with regard tojurisdictional claims in published maps and institutionalaffiliations.

The online version of the original article can be found at https://doi.org/10.1007/s12117-018-9342-y https://doi.org/10.1007/s12117-018-9345-8 https://doi.org/10.1007/s12117-018-9356-5 https://doi.org/10.1007/s12117-018-9350-y https://doi.org/10.1007/s12117-018-9335-X https://doi.org/10.1007/s12117-018-9353-8

\section{Springer Nature}

1 New York, NY, USA 